\title{
Prenatal diagnosis of 22q11 deletions: a series of five cases with congenital heart defects
}

\author{
F L Raymond, J M Simpson, C M Mackie, G K Sharland
}

\begin{abstract}
We report a series of five patients with congenital heart defects in whom a prenatal diagnosis of 22q11 deletion has been made. The accurate cardiac and cytogenetic diagnoses were made between 20 and 23 weeks' gestation in all cases and the cardiac findings were all confirmed postnatally. The cardiac abnormalities included tetralogy of Fallot with absent pulmonary valve, pulmonary atresia with VSD, common arterial trunk, and left atrial isomerism with double outlet right ventricle. The problems of genetic counselling in these cases are discussed. A recommendation is made to test all fetuses with conotruncal heart abnormalities detected prenatally for a $22 \mathrm{q} 11$ deletion, whereas guidelines for other congenital heart disease types are less clear.

(F Med Genet 1997;34:679-682)
\end{abstract}

Keywords: 22q11 deletion; prenatal diagnosis; fetal heart; echocardiography

A consensus is emerging that the incidence of $22 \mathrm{q} 11$ deletion syndrome is approximately 1 in 5000-10 000 births. $^{12}$ This makes $22 \mathrm{q} 11$ deletion syndrome one of the more common genetic diseases in the population. As a high proportion of people with 22q11 deletion have heart abnormalities, an important way in which fetuses with $22 \mathrm{q} 11$ deletion will present is through the detection of congenital heart disease. With the advent of high resolution ultrasound and specialist fetal cardiology, accurate and early prenatal diagnosis of cardiac abnormalities is now possible.

We report a series of five fetuses in whom an early prenatal diagnosis of a specific cardiac defect was made between 20 and 23 weeks' gestation and in whom a submicroscopic deletion within chromosome 22q11 was identified. On the basis of this series we provide initial guidelines for testing for 22q11 deletion in fetuses with congenital heart disease.

\section{Case reports}

CASE 1

This was the fourth pregnancy of nonconsanguineous parents. The mother was referred for a fetal cardiology opinion following the detection of a cardiac abnormality on a routine anomaly scan at 20 weeks of pregnancy. Detailed fetal echocardiography confirmed congenital heart disease, with a large ventricular septal defect, overriding of the aortic valve, and pulmonary atresia. The left kidney was also absent.

Amniocentesis was performed and a fetal karyotype of 46,XX was established using conventional $\mathrm{G}$ banding. A microdeletion of $22 \mathrm{q} 11$ region was detected using fluorescent in situ hybridisation (FISH) with Oncor N25 probe, which maps within the DiGeorge critical region at D22S75. ${ }^{3}$ This had arisen de novo.

Postnatal echocardiography and angiography confirmed the prenatal cardiac findings. No central pulmonary artery confluence was found and pulmonary blood supply was via four major aortopulmonary collateral arteries (MAPCAs). The baby is now 2 years of age with developmental delay. She crawls but is not walking and there are no intelligible words. There are severe feeding problems and she is fed through a gastrostomy as oral intake is so poor largely because of difficulty in swallowing. The degree of failure to thrive is out of proportion to her cardiac disability. Height and weight are $78.5 \mathrm{~cm}$ and $9 \mathrm{~kg}$ respectively (below the 3rd centile).

CASE 2

This was the first pregnancy of nonconsanguineous parents who were referred for fetal cardiology assessment following the suspicion of a cardiac defect on a routine anomaly scan at 20 weeks of pregnancy. The fetal echocardiogram showed a complete atrioventricular septal defect (AVSD) with a double outlet right ventricle. In addition, there was fetal bradycardia and the inferior vena cava was interrupted. A prenatal diagnosis of left atrial isomerism was made.

In view of the cardiac findings the parents elected to terminate the pregnancy before the karyotype results. At necropsy, the prenatal ultrasound findings were confirmed and, in addition, there was polysplenia, malrotation of the bowel, absent thymus, and a multicystic left kidney. The atrial appendage morphology confirmed left atrial isomerism.

Amniocentesis was performed and the fetal karyotype of $46, \mathrm{XX}$ was established but with a 22q11 deletion detected by FISH. Paternal blood was unavailable and therefore a de novo or inherited deletion could not be distinguished.

\section{CASE 3}

This was the first child of non-consanguineous parents and congenital heart disease was detected on an anomaly scan at 20 weeks of pregnancy. The prenatal echocardiogram showed tetralogy of Fallot with absence of the 


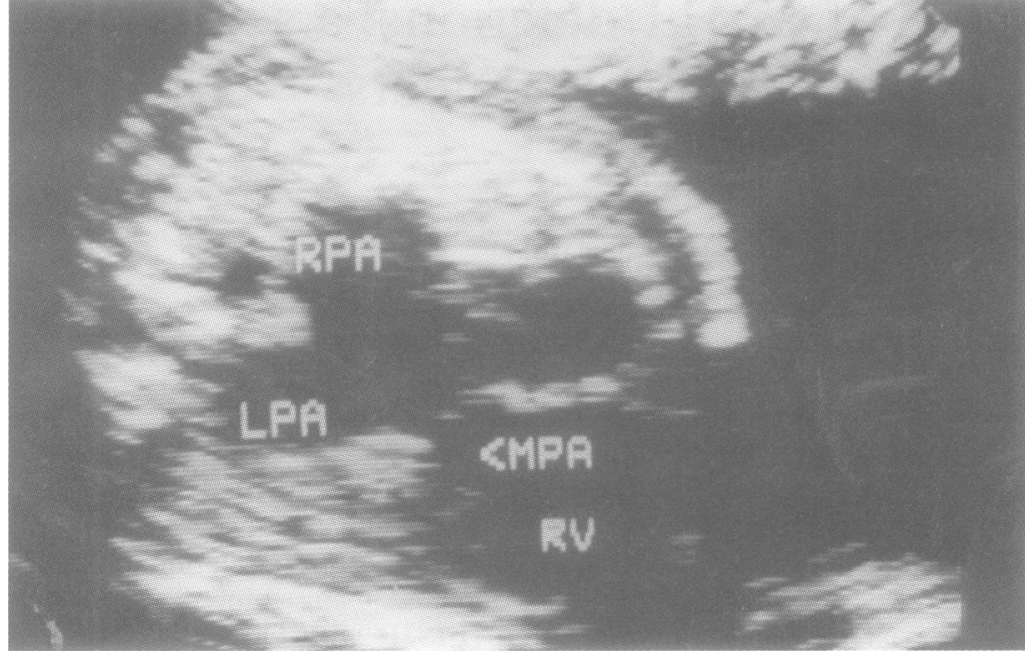

Figure 1 Prenatal echocardiographic findings in tetralogy of Fallot with absent pulmonary valve. This is a transverse echocardiographic view of the fetal thorax, at the level of the pulmonary arteries, showing the striking dilatation of the main and branch pulmonary arteries which is characteristic of the condition. $R P A=$ right pulmonary artery, $L P A=l e f t$ pulmonary artery, $M P A=$ main pulmonary artery, $R V=$ right ventricle.

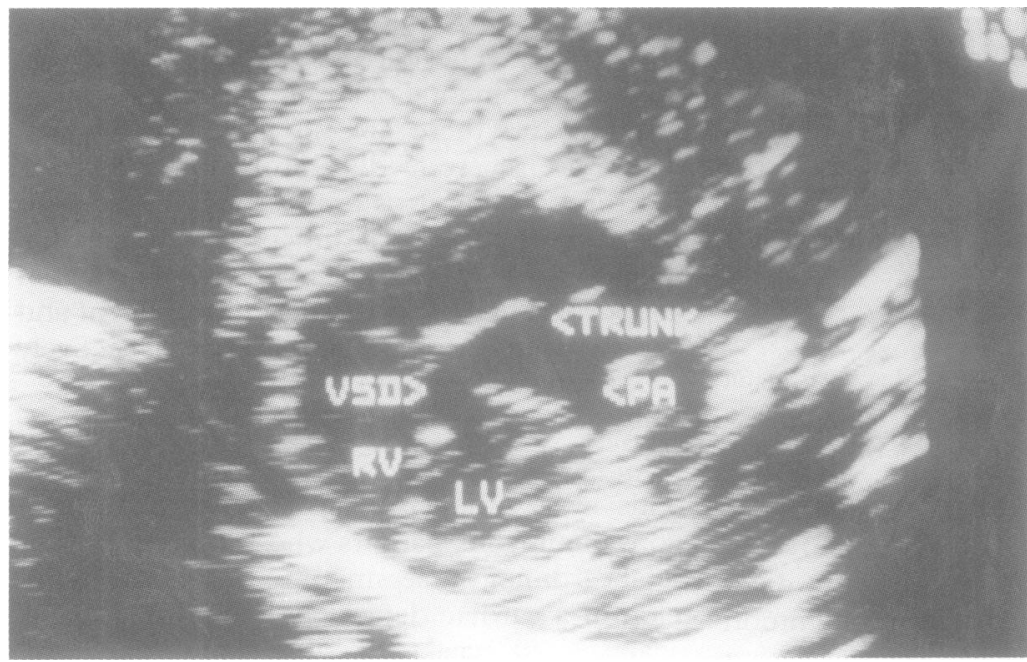

Figure 2 Prenatal echocardiographic appearances of a common arterial trunk. The common arterial trunk arises astride a ventricular septal defect. One of the branch pulmonary arteries can be seen arising from the common arterial trunk. RV=right ventricle, $L V=$ left ventricle, $V S D=$ ventricular septal defect, Trunk $=$ common arterial trunk, $P A=$ branch pulmonary artery.

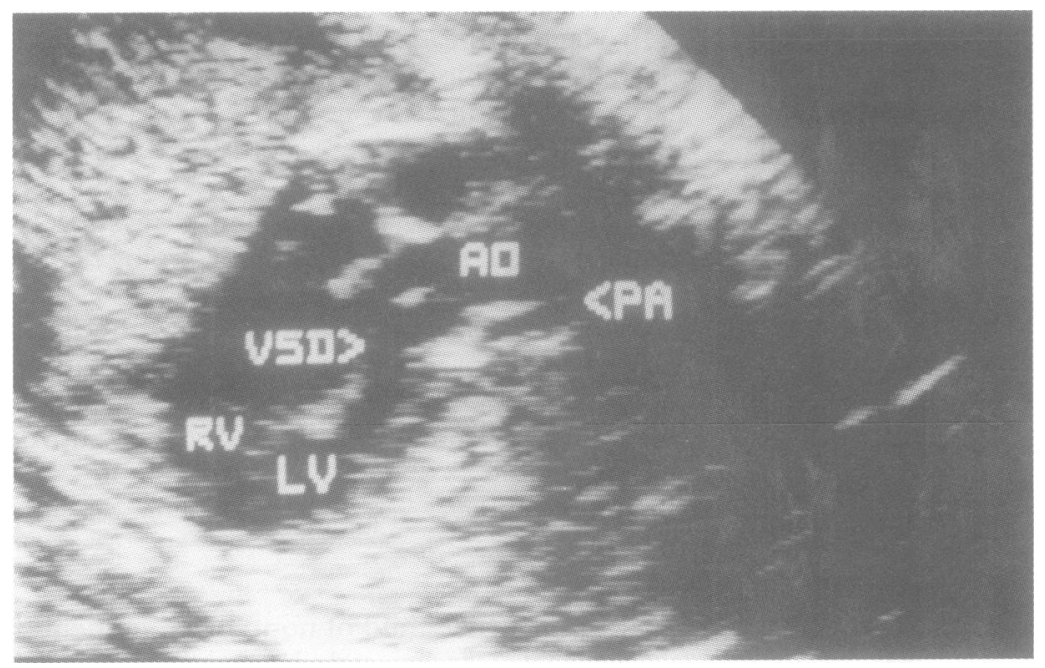

Figure 3 Prenatal echocardiographic findings of pulmonary atresia with a ventricular septal defect. The aorta overrides a ventricular septal defect. The main pulmonary artery is hypoplastic and may be seen just to the right of the aorta. $R V=$ right ventricle, $L V=$ left ventricle, $V S D=$ ventricular septal defect, $A o=$ aorta, $P A=$ main pulmonary artery. pulmonary valve. The severe dilatation of the branch pulmonary arteries is shown in fig 1.

Amniocentesis was performed and the fetal karyotype was $46, \mathrm{XX}$ with a de novo $22 \mathrm{q} 11$ deletion. The parents elected to continue the pregnancy and the baby was born at term following induction of labour. The baby was intubated and ventilated shortly after birth. Postnatal echocardiography confirmed the prenatal findings and the chest $x$ ray showed "air trapping" which was attributed to the grossly distended pulmonary arteries. Surgical repair of the defect, including VSD closure and plication of the pulmonary arteries, was performed on day 5 but the child died later the same day.

CASE 4

Referral for a detailed fetal echocardiogram was made at 22 weeks' gestation following a suspicion of congenital heart disease on a routine ultrasound scan. The cardiac findings were of a common arterial trunk with separate origins of the pulmonary arteries (truncus arteriosus, type 2). Fig 2 shows the fetal echocardiographic findings.

Amniocentesis was performed and the fetal karyotype was $46, \mathrm{XX}$ with a de novo $22 \mathrm{q} 11$ deletion. The baby was delivered at 38 weeks' gestation, and the postnatal echocardiogram confirmed the prenatal findings. This baby is clinically well at the age of 1 week with hypocalcaemia and reduced $T$ cell numbers and is awaiting corrective surgery.

CASE 5

This was the first pregnancy of nonconsanguineous parents who were referred for a fetal cardiology opinion at 22 weeks' gestation. The prenatal echocardiogram showed a large ventricular septal defect with overriding of the aortic valve and pulmonary atresia. Confluence of the pulmonary arteries was seen prenatally. The fetal echocardiogram is shown in fig 3 .

Amniocentesis was performed and the fetal karyotype was $46, \mathrm{XY}$ with a de novo $22 \mathrm{q} 11$ deletion by FISH. Labour was induced at 39 weeks and the cardiac findings were confirmed by postnatal echocardiography and angiography. Cardiac catheterisation showed small but confluent central pulmonary arteries and the lungs were supplied with blood by four MAPCAs. The baby had dysmorphic facial features characteristic of the 22q11 deletion syndrome, generalised hypotonia, considerable feeding difficulties, and reduced $T$ cell numbers. At 3 months, he was admitted for management of cardiac failure, and at 5 months, for repair of a right inguinal hernia. At that time, a laparotomy was perfomed because of persistent vomiting and adhesions around the duodenum were found and released. Feeding difficulties have continued and contrast studies have shown gastro-oesophageal reflux. At 13 months his height and weight are well below the $3 \mathrm{rd}$ centile $(67 \mathrm{~cm}$ and $6 \mathrm{~kg}$ respectively). $\mathrm{He}$ is fed nasogastrically and requires total parenteral nutrition (TPN). He remains normocalcaemic. His $\mathrm{T}$ cell populations are 
reduced; in particular CD3, 4 , and 8 populations are below normal levels. Developmentally he is delayed and is not yet sitting independently. He also has few words.

\section{Discussion}

There has been, to our knowledge, only one previous report of prenatal detection of a chromosome 22q11 deletion in a family where a previous child had a common arterial trunk (truncus arteriosus) and DiGeorge syndrome. ${ }^{4}$ This is the first reported series of patients in whom prenatal diagnosis of 22q11 deletion has been made following the prenatal detection of cardiac defects. The cardiac and cytogenetic diagnoses were made between 20 and 23 weeks of gestation in all cases, and the cardiac findings were all confirmed postnatally. Four of the five cases had cardiac abnormalities within a conotruncal heart disease group, which has been seen previously in patients with $22 \mathrm{q} 11$ deletion..$^{5-7}$ We confirm the high incidence of aortopulmonary collateral vessels, observed in pulmonary atresia with ventricular septal defect, in patients with a chromosome 22q11 deletion. ${ }^{8}$ Furthermore, one of our cases had no confluent central pulmonary arteries, which is not uncommon in patients with a $22 \mathrm{q} 11$ deletion, but is rare in the absence of a deletion. ${ }^{8}$ The one unusual case of left atrial isomerism with double outlet right ventricle has been reported elsewhere.

Devriendt $e t a l^{10}$ prospectively analysed 150 patients with conotruncal heart disease and suggested that a recognisable $22 \mathrm{q} 11$ deletion accounts for at least $12.8 \%$ of all cases of conotruncal disease diagnosed postnatally. This represents a significant number of patients in whom a cause for a congenital heart disease can be found. Detection of conotruncal abnormalities can be technically difficult prenatally but detailed echocardiography can show them. At this centre we currently detect approximately 20-25 new cases per year.

With the increasing availability of specialist fetal cardiology services, prenatal diagnosis of deletion 22q11 will become more commonplace and should be offered. The challenge to clinical geneticists is to provide appropriate and accurate genetic counselling for this condition. At present, the most useful guide to prognosis is a review of 120 patients with velocardiofacial syndrome. ${ }^{11}$ This study, however, is limited as the sample size was small, not all the patients had proven 22q11 deletion by FISH, and they were ascertained by virtue of their palatal or pharyngeal problems. The patients described here, who have been diagnosed prenatally, represent a different clinical spectrum ascertained by virtue of their congenital heart disease. The degree of learning difficulties in this group of patients is not known. Currently, we provide the best available information when counselling patients but there is a clear need for more long term prognostic information about 22q11 deletion syndrome. In particular, parents are most concerned about the possible learning difficulties and psychiatric problems reported in velocardiofacial syndrome. A matched longitudinal study of children with the same cardiac defect with or without $22 q 11$ deletion is needed as only then can the additional load of 22q11 deletion on children with major cardiac defects be fully assessed. Once established, more accurate information can be given to parents when a $22 \mathrm{q} 11$ deletion is detected prenatally. One out of five sets of parents elected to terminate the pregnancy and this was entirely on the basis of the abnormal cardiac findings. The termination was in fact performed before the results of the karyotype were available. In this series, therefore, the presence or absence of 22q11 deletion did not greatly influence the parents' decision to continue with or opt for a termination of pregnancy. However, the additional information gained about the prognosis of children with 22q11 deletion may well be helpful to parents when coming to terms with and preparing to care for a child with substantial medical problems. All our parents, except the father of case 2 who was unavailable, were tested and found to be negative for $22 \mathrm{q} 11.2$ microdeletions. Also, detection of de novo 22q11 deletion in a fetus helps in counselling in future pregnancies. In these cases, the recurrence risk is extremely low, although a case of germinal mosaicism has been reported. ${ }^{12}$ Without this information the couple would usually be given a 3-5\% recurrence risk for all cardiac defects. ${ }^{13}$

On the basis of this series various recommendations for clinical practice can be made. Firstly, as conotruncal heart defects can be detected prenatally and as approximately $13 \%$ are thought to result from deletions in chromosome $22 \mathrm{q} 1{ }^{10}{ }^{10}$ testing all fetuses with conotruncal defects for 22q11 deletion would seem appropriate. Detecting a 22q11 deletion has important implications in the clinical management of the baby postnatally.

It is not known, however, what proportion of other types of congenital heart disease have $22 q 11$ deletion and indeed one of the cases in this series had a complex heart arrangement not previously associated with $22 \mathrm{q} 11$ deletion. Until a detailed prospective study to establish the incidence of 22q11 deletion in prenatally detected congenital heart disease is complete, it will not be possible to provide clear recommendations for prenatal screening of other groups of congenital heart disease. ${ }^{14}$

We would like to thank Mr D Maxwell, Mr A Cook, Mr D Anderson, Drs S V Hodgson, A C Berry, S A Qureshi, E J Baker, and Professor $M J$ Tynan for their clinical involvement with these patients, and the SE Thames Regional Cytogenetics service for karyotyping these cases.

1 Wilson DI, Cross IE, Wren C, Scambler PJ, Burn J, Goodship J. Minimum prevalence of chromosome 22q11 deletions. Am $\mathcal{F}$ Hum Genet 1994;55:A169.

2 Tezenas du Montcel S, Mendizabal H, Ayme S, Levy A Philip N. Prevalence of 22q11 microdeletion. $\mathcal{F}$ Med Genet 1996;33:710.

3 Morrow B, Goldberg R, Carlson C, et al. Molecular definiMorrow B, Goldberg R, Carlson C, et al. Molecular defini-
tion of the deletions in velo-cardio-facial syndrome. Am $\mathcal{F}$ tion of the deletions in velo-cardio-facial syndrome. Am $\mathcal{F}$
Hum Genet 1995;56:1391-403.

4 .

Van Hemel JO, Schaap C, Van Opstal D, Mulder MP, Niermeijer MF, Meijers JHC. Recurrence of DiGeorge syndrome: prenatal detection by FISH of a molecular 22q11 deletion. 7 Med Genet 1995;32:657-8.

5 Trainer AH, Morrison N, Dunlop A, Wilson N, Tolmie J. Chromosome 22q11 microdeletions in tetralogy of Fallot. Arch Dis Child 1996;74:62-3.

6 Seaver LH, Pierpont JW, Erickson RP, Donnerstein RL Cassidy SB. Pulmonary atresia associated with materna 
22q11.2 deletion: possible parent of origin effect in the conotruncal anomaly face syndrome. 7 Med Genet 1994;31: 830-4.

7 Goldmuntz E, Driscoll D, Budarf ML, et al. Microdeletions of chromosomal region 22q11 in patients with conotruncal cardiac defects. F Med Genet 1993;30:807-12.

8 Momma K, Kondo C, Matsuoka R. Tetralogy of Fallot with pulmonary atresia associated with chromosome 22q11 pulmonary atresia associated with chrom

9 Yates RWM, Raymond FL, Cook A, Sharland GK. IsomerYates RWM, Raymond FL, Cook A, Sharland GK. Isomerism of the atrial appendages associat

10 Devriendt K, Eyskens B, Swillen A, Dumoulin M, Gewillig $M$, Fryns JP. The incidence of deletion in chromosome $22 \mathrm{q} 11$ in sporadic and familial conotruncal heart disease. Eur $\mathcal{F}$ Pediatr 1996;155:721.
11 Goldberg R, Motzkin B, Marion R, Scambler PJ, Shprintzen $R$. Velo-cardio-facial syndrome: a review of 120 patients. Am $\mathcal{F}$ Med Genet 1993;45:313-19.

12 Sitch FL, James RS, Cockwell AE, Hatchwell E. Gonadal mosaicism for a submicroscopic deletion of chromosome region 22q11. Eur f Hum Genet 1996;4(suppl 1) 59.

13 Allan LD, Crawford DC, Chita SK, Anderson RH, Tynan MJ. Familial recurrence of congenital heart disease in a prospective series of mothers referred for fetal echocardiography. Am f Cardiol 1986;58:334-7.

14 Raymond FL, Mackie CM, Simpson JM, Sharland GK. Incidence of 22q11 deletion and karyotype abnormalities detected prenatally. $f$ Med Genet 1996;33:S25. 